\title{
ATYPICAL PERNICIOUS ANAEMIA
}

By Allan Jacobs, M.D.

Department of Pathology, Paddington General Hospital

It is usually accepted that Addisonian pernicious anaemia is associated with achylia gastrica and most accounts of the disease emphasize the invariable presence of histamine-fast achlorhydria on gastric analysis. Atrophy of the gastric mucosa and absence of intrinsic factor secretion have also been held to be essential to the diagnosis. Recent work has shown that, in fact, the picture is quite variable in the classical disease and atypical cases may arise in which gastric atrophy and achlorhydria are absent and even some power of intrinsic factor secretion may remain.

\section{The Gastric Mucosa}

It has long been stated that the mucosa of the body of the stomach is atrophied in pernicious anaemia and it is generally thought that this atrophy is constitutional in origin. In recent years this view has been largely based on the work of Magnus (1952), who examined the stomachs of patients with pernicious anaemia post-mortem having fixed the mucosa as soon after death as possible. In 17 cases examined in this way atrophy of the stomach was found without evidence of inflammation. It was believed that this noninflammatory atrophy was the characteristic finding and was pathognomonic of the disease. The method of investigation had two serious disadvantages: firstly, only a small number of patients could be examined; and, secondly, they were inevitably those who had suffered from the disease for many years. It is likely that not only was this sample unrepresentative of the pernicious anaemia population, but it selected those with the most advanced lesions.

Joske, Finckh and Wood (1955), using the flexible gastric biopsy tube, were able to report on the mucosal appearance in living patients. Of 100 cases of pernicious anaemia reported, only 40 had complete gastric atrophy, while the remaining 60 had varying degrees of gastritis and atrophy. It seems, therefore, that the gastric lesion may not be as severe as had been thought, and, in fact, even in the most severe atrophy some chief cells and parietal cells may be found. The complete non-inflammatory atrophy previously thought to be pathognomonic of pernicious anaemia is now known to occur also in iron-deficiency anaemia and even in normal symptomless subjects (Magnus, 1958).

\section{The Gastric Acid}

The presence of a histamine-fast achlorhydria has long been considered a sine qua non for the diagnosis of pernicious anaemia. A practical difficulty is that there is no accepted definition of achlorhydria. Various $p \mathrm{H}$ levels have beee assumed to indicate the presence of acid secretion from $p \mathrm{H} 8.2$ (Shay et al., 1950) to $p \mathrm{H}_{3.5}$ (Winkel ${ }^{\mathrm{D}}$ stein, 1942). Other workers have adopted values between these limits, while those laboratories $\mathbb{D}$ testing their gastric juice with thymol blue as a indicator can have ' achlorhydria' at $p \mathrm{H}$ r.2.

An investigation of 79 cases of classical pero nicious anaemia showed the $p \mathrm{H}$ of the resting gastric juice to vary between 8.9 and 5.0. On stimulation of the stomach by a standard histamine test meal most of the patients responded by producing a more acid gastric juice (Jacobs, I958). The varieties of response are illustrated in the figure.

The traditional distinction between the presense and absence of ' free acid ' made by applying an arbitrary $p \mathrm{H}$ level has no real significance and its use in the diagnosis of pernicious anaemia has no theoretical justification. Complete achlorhydria is not invariable in pernicious anaemia and minor degrees of acid secretion may be found, merging at one end of the scale with the normal. The gastric secretory response may vary from time to time in the same patient. The incidence of ' achlorhydria' in pernicious anaemia depends entirely on the criterion adopted (Jacobs, 1958).

\section{Intrinsic Factor}

Pernicious anaemia has been defined as the failure of secretion of intrinsic factor, with consequent inability to absorb vitamin $\mathrm{B}_{12}$. Since Castle's original observations this has been considered very much an all-or-none phenomenon 


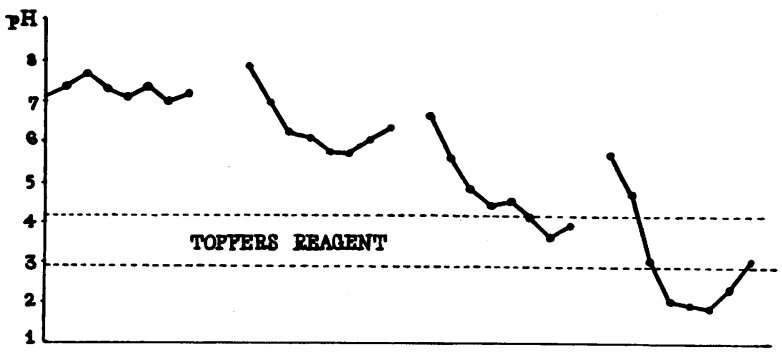

Fif. 1. PHI abange during four fractional test meals in different cases of pernicious anaemia

and the detection of intrinsic factor has thrown doubt on a diagnosis of pernicious anaemia. Castle himself, however, noted that the gastric secretions often returned during a spontaneous remission of the disease, indicating a hidden potential in the patient's stomach. Goldhamer (1936) obtained gastric juice from five cases of untreated pernicious anaemia, which he pooled and fed to another patient over a period of ro days with $200 \mathrm{~g}$. of meat daily. He produced a therapeutic response, thus demonstrating that intrinsic factor was present albeit in a low concentration. This finding has been confirmed more recently using radio-active vitamin $B_{12}$ absorption as a measure of intrinsic factor (Mollin and Baker, 1955). Residual intrinsic factor secretion is more often found in early cases of pernicious anaemia (Mollin, 1959) and in a few cases almost normal amounts of secretion may occur on stimulation (Harris-Jones et al., 1957; Mollin et al., 1955).

\section{Atypical (Incomplete) Pernicious Anaemia}

The early stages in the development of pernicious anaemia are not understood. Achlorhydria and gastric atrophy have been shown to precede pernicious anaemia in some cases, but these phenomena commonly have no sequelae. Some

TABLE

Cases of Pernicious Anaemia with Normal Gastric ACIDITY

\begin{tabular}{|c|c|c|c|c|}
\hline Author & $\left|\begin{array}{l}\text { Age of } \\
\text { Patient }\end{array}\right|$ & $\begin{array}{l}\text { Gastric } \\
\text { Mucosa }\end{array}$ & $\begin{array}{c}\text { Acid } \\
\text { Secretion }\end{array}$ & $\begin{array}{c}\text { I.F. } \\
\text { Secretion }\end{array}$ \\
\hline Murphy (1948) & 23 & & Normal & Absent \\
\hline $\begin{array}{l}\text { Esteves (1952) } \\
\text { Movitt and }\end{array}$ & 64 & & Normal & Absent \\
\hline Lubeck (1953) & $4 I$ & & Normal & Reduced \\
\hline $\begin{array}{c}\text { Mollin et al. } \\
\text { (I955) }\end{array}$ & 20 & Normal & Normal & Reduced \\
\hline et al. (1957). & 16 & Normal & Normal & Reduced* \\
\hline Jacobs (1958) & 47 & & Normal & Reduced \\
\hline
\end{tabular}

* Normal after carbachol stimulation. cases of pernicious anaemia have been shown to) have normal gastric acidity (table). Rubin (r958 mentions eight cases in juveniles in whom complete lack of intrinsic factor secretion is associated with normal acid secretion.

It seems probable that early stages of the disease present an 'incomplete' clinical picture and that this is most likely in young patients. At the moment the most reliable tool in diagnosis is the measurement of intrinsic factor secretion by radioisotope techniques and in atypical cases it is on this investigation that the diagnosis depends. Even in the ' classical' case the gastric mucosal failure may not be quite absolute.

Magnus (1958) believes that the basic defect is an inborn error of metabolism, possibly resulting in the inability to manufacture an essential enzyme. The mucosal changes may be secondary to this.? If early cases of pernicious anaemia are to be recognized and the etiology investigated, then the diagnosis must not be excluded because the clinical picture is incomplete. This applies especially to young patients.

I wish to thank Dr. B. J. Leonard for reading this paper.

\section{BIBLIOGRAPHY}

GOLDHAMER, S. M. (1936), Amer. F. med. Sci., 191, 405.

HARRIS-JONES, J. N., SWAN, H. T., and TUDHOPE, G. R. (1957), Blood, 12, 46r.

JACOBS, A. (1958), Brit. F. haemat., 4, 465.

JOSKE, R. A., FINCKH, E. S., and WOOD, I. J. (1955), Quart. 7. Med., 24, 260 .

MAGNUS, H. A. (1952), in 'Modern Trends in Gastro-enterology' (ed. F. A. Jones).

MAGNUS, H. A. (1958), f. clin. Path., 11, 289.

MOLLIN, D. L. (1959), Brit. med. Bull., 15, ro.

MOLLIN, D. L., and BAKER, S. J. (1955), in 'Biochemistry of Vitamin B,', Biochem. Soc. Symposium, No. 13.

MOLLIN, D. L., BAKER, S. J., and DONIACH, I. (1955), Brit. Э. haemat., I, 278.

MOVITT, E. R., and LUBECK, G. H. (1953), Acta haemat. (Basel), 9, 370 .

MURPHY, A. (1948), Med. F. Aust., I, 521.

RUBIN, C. E. (1958), Gastroenterology, 34, 214.

SHAY, H., KOMAROV, S. A., and BERK, J. E. (1950), Ibid., I5, 10. TRINCAO, C., and ESTEVES, F. DE V. (1952), Portugal méd.,
36, 73.

WINKELSTEIN (1942), Amer. F. med. Sci., 203, 419. 